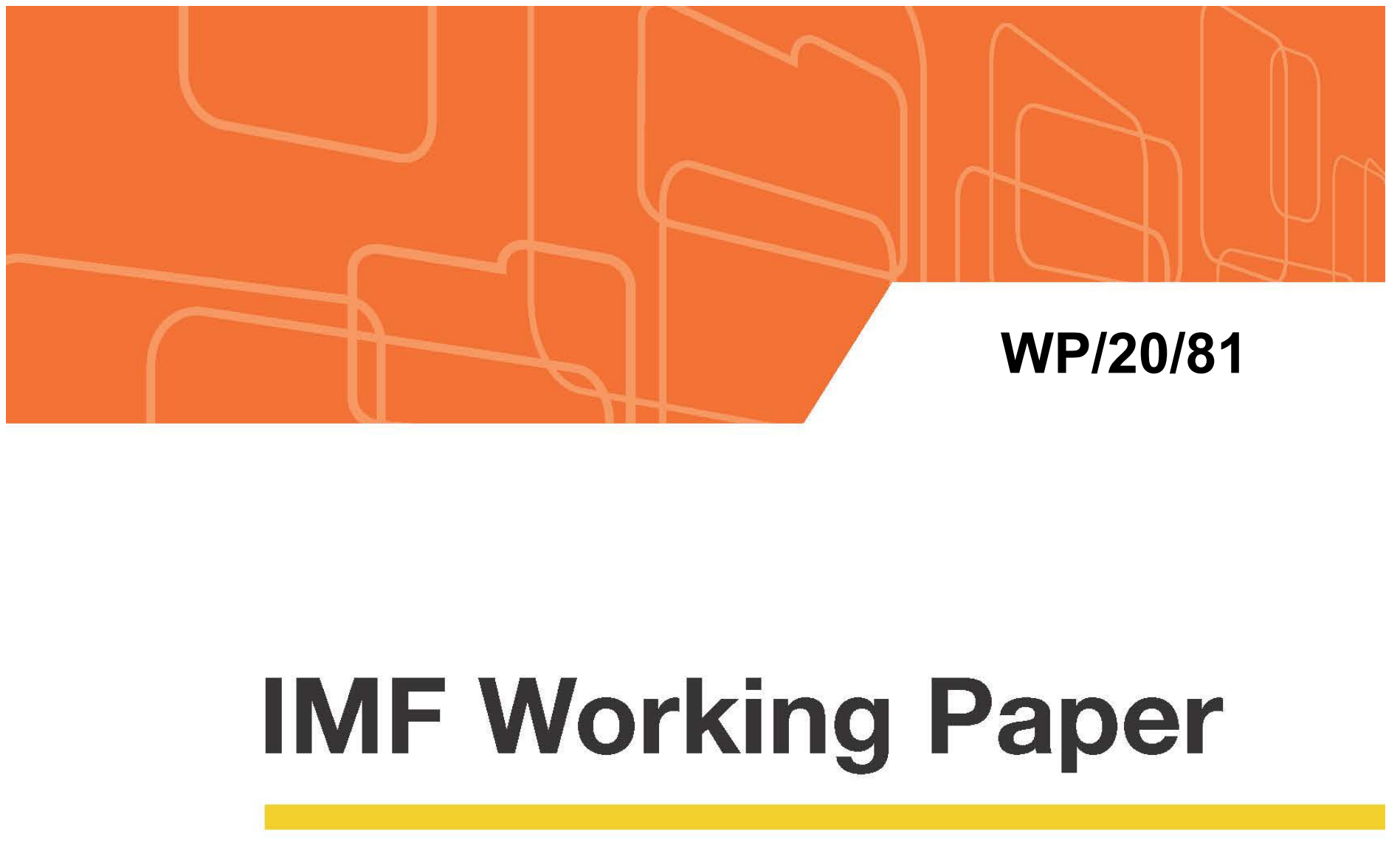

\title{
Measuring the Impact of a Failing Participant in Payment Systems
}

by Ronald Heijmans and Froukelien Wendt

IMF Working Papers describe research in progress by the author(s) and are published to elicit comments and to encourage debate. The views expressed in IMF Working Papers are those of the author(s) and do not necessarily represent the views of the IMF, its Executive Board, or IMF management. 


\title{
IMF Working Paper
}

Monetary and Capital Markets Department

\section{Measuring the Impact of a Failing Participant in Payment Systems}

\section{Prepared by Ronald Heijmans Heijmans ${ }^{1}$ and Froukelien Wendt ${ }^{2}$}

Authorized for distribution by Jihad Alwazir

June 2020

IMF Working Papers describe research in progress by the author(s) and are published to elicit comments and to encourage debate. The views expressed in IMF Working Papers are those of the author(s) and do not necessarily represent the views of the IMF, its Executive Board, or IMF management.

Disclaimer: This document was prepared before COVID-19 became a global pandemic and resulted in unprecedented economic strains. It, therefore, does not reflect the implications of these developments and related policy priorities. We direct you to the IMF Covid-19 page that includes staff recommendations with regard to the COVID-19 global outbreak.

\begin{abstract}
Banks and financial market infrastructures (FMIs) that are not able to fulfill their payment obligations can be a source of financial instability. This paper develops a composite risk indicator to evaluate the criticality of participants in a large value payment system network, combining liquidity risk and interconnections in one approach, and applying this to the TARGET2 payment system. Findings suggest that the most critical participants in TARGET2 are other payment systems, because of the size of underlying payment flows. Some banks may be critical, but this is mainly due to their interconnectedness with other TARGET2 participants. Central counterparties and central securities depositories are less critical. These findings can be used in financial stability analysis, and feed into central bank policies on payment system access, oversight, and crisis management.
\end{abstract}

JEL Classification Numbers: E42, E50, E58, E59

Keywords: Financial market infrastructures, TARGET2, liquidity risk, systemic impact, oversight, financial stability.

Author's E-Mail Addresses: ronald.heijmans@dnb.nl, fwendt@imf.org

1 De Nederlandsche Bank and Payments Canada. 2 International Monetary Fund. Heijmans is a member of one of the user groups with access to TARGET2 data in accordance with Article 1(2) of Decision ECB/2010/9 of July 29, 2010 on access to and use of certain TARGET2 data. DNB and the MIPC have checked the paper against the rules for guaranteeing the confidentiality of transaction level data imposed by the MIPC pursuant to Article 1(4) of the above-mentioned issue. The authors are grateful for the input from Janko Gorter, Hiroko Oura, Hector Perez-Saiz, Tanai Khiaonarong, Ibrahim Ergen and Argyris Kahros. The views expressed in the paper are solely those of the authors and do not necessarily represent the views of the authors' affiliations. All remaining errors are the authors' responsibility. 


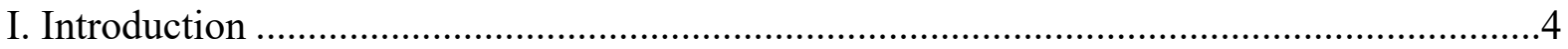

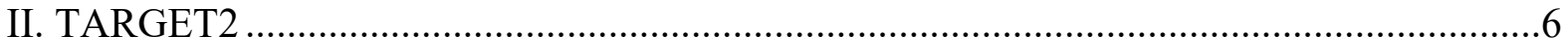

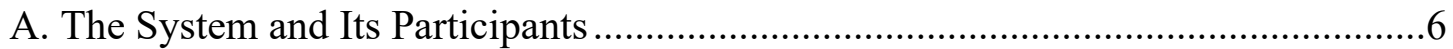

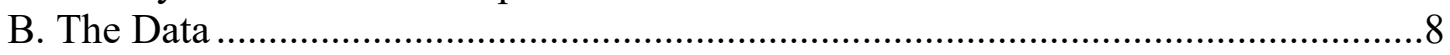

III. Composite Indicator for Liquidity Risk and Systemic Impact ..................................10

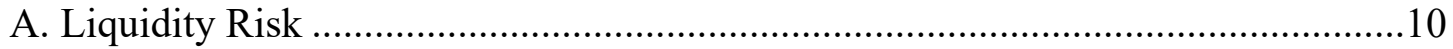

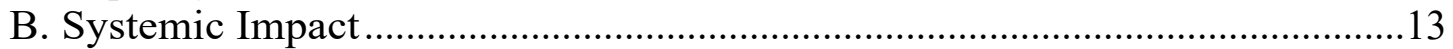

C. Combined Liquidity Risk and Systemic Impact ............................................ 13

IV. Application of Composite Risk Indicator to TARGET2 …......................................... 15

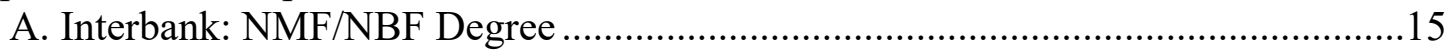

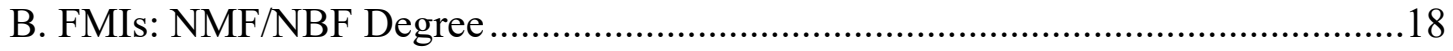

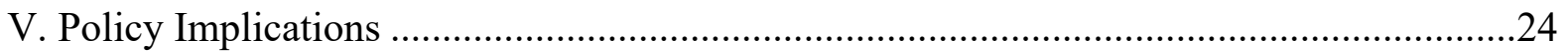

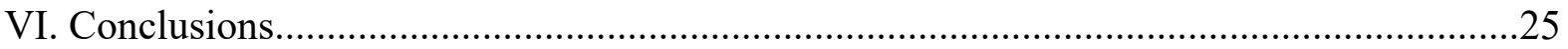

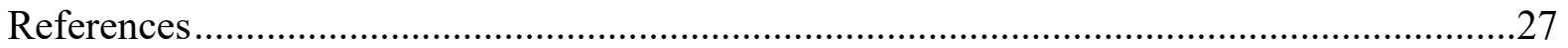

Tables

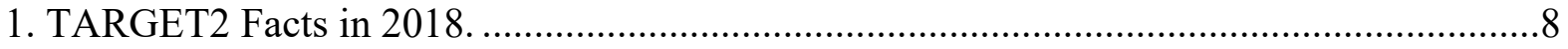

2. Indicative Netting Factor per FMI Type .................................................................. 10

Figures

1. Schematic Example of Payment Flows in a Three-Participant System ............................13

2. Schematic Illustration of Measuring Level of Criticality ................................................ 14

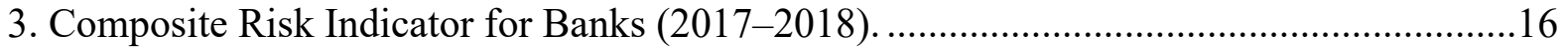

4. Composite Risk Indicator for Banks (2018:Q4) ..........................................................18

5. Composite Risk Indicator for FMIs (2018) .............................................................. 19

6. Composite Risk Indicator for FMIs (2018:Q4) ......................................................21

7. Composite Risk indicator for FMIs, Adjusted for Netting Factor (2018:Q4) ..................23 


\section{INTRODUCTION}

Financial market infrastructures (FMIs) facilitate the clearing and settlement of financial obligations of financial institutions and their customers. If FMIs, such as large value payments systems (LVPSs) and central counterparties (CCPs), do not function properly they can significantly disrupt the financial system and can be a source of contagion. Therefore, due to their importance, FMIs have to comply with international standards laid down in the Principles for Financial Market Infrastructures (PFMI) developed by international standard setting bodies (CPSS-IOSCO, 2012).

Determining the systemic importance of FMIs and other financial institutions in a network is instrumental to better understand contagion risks and to gauge the impact of an FMI's failure on the economy or, vice versa, the impact of a financial institution's failure on FMIs (Wendt, 2015). Not long ago, network analysis typically modeled transactions between financial institutions without accounting for FMIs, assuming that FMIs will always function properly, which is not necessarily the case. FMIs can suffer from outages, as occurred in the United Kingdom in 2014 (Bank of England, 2015), or from defaulting participants, as happened at Nasdaq Clearing in 2018. Such incidents may propagate liquidity and credit risks through the financial system and impact the broader economy. FMIs can also be hit by cyber-attacks, which disrupt operations, either directly or indirectly through participants' operations. For example, Norges Bank was hit by a DDos attack in 2014, which resulted in suspended services during the day and subsequent liquidity exposures to other participants (Bouveret, 2018). ${ }^{1}$

This paper focuses on the network of participants of a large value payment system (LVPS) for the settlement of payment transactions. The LVPS network represents a "flow" that can be measured per unit in time, contrary to other papers that use a network of exposures reflecting a "stock," a quantity at a certain point in time. Our paper develops a composite risk indicator capturing both liquidity risk and systemic impact following the failure of a financial institution in an LVPS network. A financial institution can be a bank or an FMI that settles in the LVPS. The financial institutions are the nodes or vertices in the network, whereas their payments flows are the links or edges. Failing is defined as the inability to make any payments due to, for example, an operational problem, cyber-attack, severe power outage, operational fraud, or bankruptcy. The difference between the incoming and outgoing payments is a measure for liquidity risk. This is measured at macro level (the difference between all incoming and outgoing payments), or at micro level (bilateral flows between two participants). The systemic impact is measured by the degree of a participant, which is its level of its interconnectedness in the payment system. Whether participants that do not receive expected liquidity can handle the shock depends to a large extent on their access to

\footnotetext{
${ }^{1}$ Such disrupted participants can be detected using an algorithm. (Klee 2010), (Glowka, Paulick, and Schultze 2018) and (Arjani and Heijmans, 2020) have developed algorithms to detect potential operational problems of participants in the United States, the Eurosystem and the Canadian large value payment system, respectively.
} 
liquidity. The indicator proposed aims to give insight into the impact on and not the shock absorbing capacity of participants.

For FMIs that settle their net positions in TARGET2, we correct for the actual underlying gross flow of their settlement instructions, which is necessary to measure the actual economic impact of their failure. Some FMIs have a netting efficiency of 98 percent leading to an actual potential impact that is 50 times larger than the flows seen in the LVPS.

As a vehicle of research, we use transaction data of the European real time gross settlement system (RTGS) for euro denominated payments, i.e., TARGET2. ${ }^{2}$ The data include transaction information of, among others, commercial banks, and different types of FMIs settling their positions in TARGET2. Our method allows for identifying TARGET2 participants (FMIs and commercial banks) that are critical and which failure may potentially cause substantial liquidity risk and/or systemic impact. Identification allows for targeted policy measures to reduce these risks. The novelty of the is paper is its inclusion of FMIs as participants in the payment system network and its differentiations between the flows seen in an LVPS and the actual underlying gross flows.

The paper builds on earlier work in this area. Berndsen and Heijmans (2020) convert TARGET2 transaction level data into indicators that provide information on operational risk, changes in the network structure and interdependencies. Heijmans and Zhou (2019) developed a univariate and multivariate method to detect outliers in these indicators. Li and Perez-Saiz (2018) developed a method to measure systemic risk across FMIs in Canada, and Squartini, van Lelyveld, and Garlaschelli (2013) develop a method that detects early warning signals of the topological collapse of the interbank network.

Our analysis adds to the growing literature on network analysis on FMIs. For example, Soramäki and Cook (2013) develop a measure SinkRank to predict the magnitude of disruption caused by the failure of a bank in a payment system and identify banks most affected by the failure. This measure is applied by Baek, Soramäki, and Yoon (2014), describing the network properties of the Korean interbank payment system (BOKWire+). Arjani, Li, and Sabetti (2020) enhance the forecasting modeling of Baek et all and apply the model to the Canadian large value payment system. Pröpper, van Lelyveld, and Heijmans (2013) provide an overview of the network properties of the Dutch RTGS payment system. Heijmans, Heuver, Lelyveld, and Levallois (2016) provide a dynamic way of looking at networks by creating a movie showing the variations in the network over time. Finally, León and Pérez (2014) couple financial institutions' multiplex networks with FMI networks, whereas Bardoscia, Bianconi, and Ferrara (2018) conduct a multiplex network analysis of the over-the-counter (OTC) derivatives market in the United Kingdom. Our approach differs

\footnotetext{
${ }^{2}$ TARGET2 stands for Trans-European Automated Real Time Gross Settlement Express Transfer.
} 
from others by combining liquidity risk and systemic impact, and by identifying the role of FMIs in an LVPS.

Our method can be used by payment system operators and overseers, financial stability experts, and other experts inside and outside central banks for financial stability analysis, adding to a trend where central banks and financial market regulators increasingly apply network analysis and stress testing of FMIs in their supervisory practices. For example, the European Securities and Markets Authority (ESMA) and the U.S. Commodity Futures Trading Commission (CFTC) initiated and coordinated stress test exercises for CCPs, to test the resilience of CCPs to adverse market developments (ESMA, 2018; CFTC, 2019), whereas the Financial Stability Board (FSB) Study Group on Central Clearing Interdependencies (FSB, 2017) explored and quantified interdependencies between CCPs, their members and other financial institutions at a global level. However, where these studies look into credit and liquidity exposures between CCPs and their participants, whereas this study focuses on payment flows in LVPS and related operational and liquidity risks.

The methodology can also be used as part of country analysis, financial sector assessment program missions, and other bilateral and multilateral surveillance activities of the International Monetary Fund (IMF), World Bank, and other institutions. It may add to network analysis already undertaken (see for example IMF, 2018).

The paper is organized as follows. Section II provides an overview of the TARGET2 system and its data. Section III describes the composite indicator for systemic and liquidity risk. Section IV applies this composite indicator to TARGET2 data. Section V provides policy recommendations and section VI concludes.

\section{TARGET2}

\section{A. The System and Its Participants}

TARGET2 is the LVPS and RTGS system for euro denominated payments owned and operated by the Eurosystem. All payments are settled one by one (gross) and on a continuous basis (real time) in central bank money with immediate finality. There is no upper or lower limit on the value of payments. TARGET2 also settles monetary policy and money market operations. Every five days, TARGET2 processes a value close to the entire euro area GDP, which makes it one of the largest payment systems in the world. Table 1 provides some key figures on TARGET2 for the year 2018. In 2018, customer payments accounted for 61 percent of the total TARGET2 traffic in terms of volume, followed by interbank payments (24 percent), ancillary system payments (9 percent) and other payments such as central bank operations (7 percent) (ECB 2019). Even though TARGET2 is a LVPS 70 percent of the transactions is below EUR 50.000 and only 10 percent is above EUR 1 million.

TARGET2 has over 1,000 direct participants, of which most are commercial banks. Other participants are central banks of the Eurosystem, some central banks in the European Union 
not having the euro, and national treasuries. In addition, FMIs can participate in TARGET2 as so-called ancillary systems (ASs) to settle (net) cash positions resulting from their clearing and settlement business. The ASs that participate in TARGET2 are: i) automated clearing houses (ACH); ii) CCPs; iii) the continuous linked settlement (CLS) system; iv) Euro1; and v) securities settlement systems (SSS) and central securities depositories (CSDs). At the end of 2018, a total of 85 ancillary systems were settling on the TARGET2 platform, including 31 retail payment systems, 21 securities settlement systems, and 23 clearing houses (including four CCPs) and others.

The number of FMI participants in TARGET2 reported by the ECB differs from numbers in our data. The ECB reports 31 retail payment systems, whereas our data finds fewer, because we do not label different so-called ancillary system interfaces (ASIs) as different payment systems, where different ASIs are used for the same retail payment system that is active in multiple countries and/or provides different types of services. Given our data structure we are not able to distinguish between the different services a payment system provides. The number of CCPs reported by the ECB is 4, whereas we find more. Some CCPs have a bank license and can be seen as a bank rather than a CCP, however, since their business activity is that of a CCP we have labeled them as such.

An $\mathrm{ACH}$ is an electronic clearing system in which payment orders are exchanged among participants (primarily via electronic media) and handled by a data-processing center. ACHs typically process retail related payments such as credit transfers and direct debits between commercial banks. ACHs are designed for high-volume, low-value payments, and settle transactions on a deferred net basis, to reduce liquidity needs of member banks, with one or multiple settlement batches per day. Lately, retail payments can also be settled through instant payment arrangements with direct settlement between banks in TARGET2, with the possibility to circumvent settlement through ACHs. ${ }^{3}$

A CCP is an entity that interposes itself, in one or more markets, between the counterparties to the contracts traded, becoming the buyer to every seller and the seller to every buyer, and thereby guaranteeing the performance of open contracts. CCPs in Europe are settling securities, derivatives, commodities, and repos. A CCP typically nets positions of its participants on a multilateral basis, resulting in net payment transfers in the RTGS system. In addition, a CCP settles cash collateral transfers, such as margin payments, through the payment system.

\footnotetext{
3 TARGET Instant Payment Settlement (TIPS) is a new market infrastructure service launched by the Eurosystem in November 2018. It enables payment service providers to offer fund transfers to their customers in real time and around the clock, every day of the year. As settlement in TIPS takes place in central bank money, participation in TIPS depends on being eligible to access central bank money. A participant needs to fulfill the eligibility criteria of TARGET2 in order to offer TIPS services. See the TARGET2 website of the ECB for more information on TIPS.
} 
CLS provides global multi-currency settlement services settling FX contracts on a multilateral net basis using a payment versus payment (PvP) mechanism. To facilitate settlement, CLS has access to central bank money in each of the eligible currencies. Given the different time zones of the different LVPSs worldwide, participants of CLS have to transfer the required funds at pre-specified times. A delay in the euro funding could affect the multi-currency settlement of CLS and eventually other currency areas, in particular the Asia-Pacific region which, due to the time difference, is close to its end of day.

\section{Table 1. TARGET2 Facts in 2018}

\begin{tabular}{l|l} 
& \\
\hline Number of participants & $\begin{array}{l}\text { TARGET2 had } 1,056 \text { direct participants, } 659 \text { indirect } \\
\text { Participants, and } 4,091 \text { correspondents. }\end{array}$ \\
\hline Number of ancillary systems & $\begin{array}{l}\text { TARGET2 settled the cash positions of } 85 \text { ancillary systems: } \\
31 \text { retail payment systems, } 21 \text { security settlement systems } \\
\text { and } 23 \text { clearing houses (including } 4 \text { CCPs), and } 10 \text { others. }\end{array}$ \\
\hline $\begin{array}{l}\text { Number of ancillary systems } \\
\text { identified in our data }\end{array}$ & 17 retail payment systems, 20 CSDs, 12 CCPs and 3 others. \\
\hline Daily averages & $\begin{array}{l}\text { TARGET2 processed a daily average of } 346,843 \text { payments } \\
\text { representing a daily average value of EUR } 1.7 \text { trillion. }\end{array}$ \\
\hline Average transaction value & EUR 4.8 million. \\
\hline Payment values & $<50,000$ (70 percent of all TARGET2 payments) \\
& $>1$ million (10 percent of all TARGET2 payments) \\
\hline Share large value payment traffic in euro & 90 percent in value and 63 percent in volume. \\
\hline $\begin{array}{l}\text { Payments processed in less than five } \\
\text { minutes }\end{array}$ & $\begin{array}{l}<00 \text { percent } \\
<1 \text { minute (99.9 percent of all enquiries) } 1 \text { to } 3 \text { minutes } \\
\text { (0.10 percent) }\end{array}$ \\
\hline
\end{tabular}

Source: ECB.

EURO1 is an LVPS for cross-border and domestic transactions in euro between banks operating in the EU. This system settles its positions at the end of the day on a net basis in TARGET2. In the event that a settlement bank fails to meet its obligation in EURO1 end-ofday settlement, because of liquidity problems, a guarantee account mechanism is used.

Finally, a CSD is an entity that: i) operates an SSS that enables securities transactions to be processed and settled by book entry; ii) provides custodial services (e.g., the administration of corporate actions and redemptions); and iii) plays an active role in ensuring the integrity of securities issues. An SSS may operate independently from a CSD; but in this report, we define a CSD as the operator of an SSS. Countries participating in TARGET2 typically have at least one CSD operating in their jurisdiction. CSDs typically settle on a gross basis.

\section{B. The Data}

Our data set contains all individual transactions settled in TARGET2 since the start of the system in 2007 to December 2018. TARGET2 distinguishes between four main categories: 
1) transactions between commercial banks; 2) payments with a central bank involved; 3) payments with and AS involved; and 4) liquidity transfers. These main categories are divided into subcategories. Category 1 is divided in interbank payments on behalf of the bank's own business or that of its client. Category 2 has payment types with respect to cash operations (bank notes) or between two central banks of the Eurosystem. Category 3 differentiates between payments with i) an SSS and CCP; ii) an ACH; iii) EURO1; iv) CLS; and v) EBA Step2. The fourth category has several sub types of liquidity transfers such as internal and commercial transfers between different accounts of the same participant. For the settlement of the euro, CLS holds an account with the ECB and receives and sends euro payments via TARGET2. Berndsen and Heijmans (2020) provide more details.

Data have been aggregated to daily gross bilateral flows for each participant pair per payment subcategory. This means that there is an aggregated value of a certain payment type from participant $\mathrm{A}$ to $\mathrm{B}$ and a (different) value going from participant $\mathrm{B}$ to $\mathrm{A}$. The database allows for looking at different levels, which are i) account level (each account individually); ii) institutions (aggregation of accounts belonging to one institution); and iii) country level (aggregation of accounts of all participants be- longing to one responsible central bank in TARGET2). As the focus of this paper is to measure the impact of a failing institution at the level of a (legal) institution, we focus only on the institutional level (level ii).

For the purposes of this analysis, only payment types 1 and 3 are included, reflecting all payment activities of commercial banks and FMIs. The flows of payment types 1 and 3 observed in TARGET2 are different in their economic nature. Generally, the value of category 1 payment seen in TARGET2 also reflects the underlying economic value. However, the payments with an FMI (AS) involved are often the result of a netting process in the FMI (category 3.1 to 3.5). Only the final positions after netting are settled in TARGET2. This means that the actual underlying economic activity of a payment from or to an FMI can be much larger than the actual flow.

Table 2 shows the indicative netting percentages per FMI type. For example, one euro not send to CLS potentially means an actual missing value of EUR 100 due to the netting efficiency of that system. EURO1 is in fact not a netting system as payments are settled on a gross basis between participants with a debit/credit cap of EUR 1 billion. However, the flows we see from TARGET2 to EURO1 are often the net flows of the EURO1 participants. We will use these netting percentages to calculate the potential underlying economic impact of a disruption. As CLS, EURO1 and EBA STEP2 belong to one institution we will discuss them as a group for confidentiality reasons. 
Table 2. Indicative Netting Factor per FMI Type

\begin{tabular}{l|c|c|c}
\hline FMl type & $\begin{array}{c}\text { Netting } \\
\text { percentage }\end{array}$ & $\begin{array}{c}\text { Underlying } \\
\text { economic } \\
\text { impact factor }\end{array}$ & Source \\
\hline ACH & 98 & 50 & Expert judgement. \\
\hline CCP & 66 & 3 & Rosati and Secola, 2005 \\
\hline CSD & 0 & 1 & $\begin{array}{c}\text { Assumption that CCP settle securities on a } \\
\text { net basis and CSDs settle securities on a } \\
\text { gross basis. }\end{array}$ \\
\hline Other (CLS, & 96 & 25 & $\begin{array}{c}\text { Stated by CLS and also used for EURO1 } \\
\text { and EBA Step2. }\end{array}$ \\
\hline Interbank payment & 0 & 1 & By definition, no netting. \\
\hline
\end{tabular}

Source: Authors.

The netting factors are indicative and meant to illustrate the potential underlying economic impact of an FMI's failure. In practice, netting factors may vary across CCPs, and ACHs and even within a CCP, ACH, or CLS from day to day. Depending on the business cleared the netting factor may be close to 99 percent one day and not even 20 percent on another day. However, given the underlying euro values of the different FMIs, the outcome of our analysis will show similar results.

An aspect left out of the analysis is the impact of a failure of FMI participants and how this subsequently impacts the performance of the FMI in TARGET2. For example, in the case of the failure of a CCP participant, the CCP will no longer have a matched book. As long as the CCP can cover these losses with prefunded capital, such as margins and a default fund, a CCP will be able to absorb the shock and there is no failure of the CCP. Only if the CCP is not able to absorb the shock it may default as well, which then is covered by our analysis.

\section{COMPOSITE INDICATOR FOR LIQUIDITY RISK AND SYSTEMIC IMPACT}

This section describes the method used to measure the impact of a bank or FMI that is not able to make payments in TARGET2. First, the liquidity risk measure is described in section A. Section B describes the measure for systemic impact. In section $\mathrm{C}$ we define a composite risk indicator combining the liquidity risk and systemic impact to determine a participant's criticality to the payment system. Section D makes the connection to the common economic approach for defining systemically important financial institutions.

\section{A. Liquidity Risk}

In this paper, liquidity risk is defined as the risk that a failing participant in a payment system poses to other participants when it is not able to settle its payment obligations in full when due, although it may be able to do so in the future. Liquidity risk can be measured at a macro 
level using the net multilateral flow (NMF). The NMF is the total amount of liquidity sent minus the liquidity received by the failing participant and is defined by:

$$
N M F_{i}=\sum_{j=1, i \neq j}^{N} a_{i j}-\sum_{j=1, i \neq j}^{N} a_{j i}
$$

where $\mathrm{j}$ are the other banks, bank i pays to or receives from, $\mathrm{N}$ is the number of banks in the system, $a_{\mathrm{ij}}$ the outgoing payments from bank $\mathrm{i}$ to bank $\mathrm{j}$ and $\mathrm{aji}_{\mathrm{ji}}$ are the incoming payments from bank $j$ to bank $i$. The flows from bank $i$ to itself are ignored. The NMF can be seen as the net in or outflow of bank $i$ on a given day.

In case the NMF is positive, the failing bank was supposed to pay more that day than it was about to receive. This is the liquidity the system will be lacking, even when the other banks do not send any payments to the failing bank. In case the NMF is negative the failing participant received more that day than it paid out to other participants. In sum, the NMF measure gives insights in the impact of a failing participant on the liquidity in the system as a whole.

However, the impact on the system as a whole is not a good indicator of the impact that the failing bank has on individual participants. Even if the NMF equals zero, individual banks may be affected by the failing bank. It is likely that there that are participants that are expected to receive more liquidity from the failing bank than they pay (and vice versa). As a consequence, these participants may not be able to fulfil all their obligations. Therefore, we also consider the net bilateral flows (NBF) as defined by Berndsen and Heijmans (2020). The NBF of one participant pair reflects the remaining net liquidity flow between these two participants if all gross payment flows are netted on a daily basis. The NBF can be positive or negative. A positive NBF means that on a bilateral net basis the failing participant has to pay out more than it receives and a negative NBF means that incoming payments for the failing participant are higher than the outgoing.

We distinguish the contribution between a positive and negative NBF. A positive NBF

$\left(\mathrm{NBF}_{\mathrm{pos}}\right)$ includes only those participant pairs with whom the failing bank has a positive outflow (it pays those banks more than it receives from them). A negative NBF ( $\mathrm{NBF}_{\text {neg }}$ ) includes only those participant pairs with whom the failing bank has a positive inflow (it pays those banks less than it receives from them). 
The $\mathrm{NBF}_{\text {pos }}$ for bank $\mathrm{i}$ is defined by:

$$
N B F_{\text {pos }, i}=\sum_{j=1, i \neq j}^{N} a_{i j}-\sum_{j=1, i \neq j}^{N} a_{j i} \text { for } a_{i j}>a_{j i}
$$

The NBF neg for bank $i$ is defined by:

$$
N B F_{n e g, i}=\sum_{j=1, i \neq j}^{N} a_{i j}-\sum_{j=1, i \neq j}^{N} a_{j i} \text { for } a_{i j}<a_{j i}
$$

where the equation elements are the same as for Equation (1) on the $\mathrm{NMF}_{\mathrm{i}}$.

A participant that is not able to meet its obligations will cause liquidity shortages at its counterparts. At the same time the liquidity sent to the failing participant will (temporarily) disappear in a liquidity "sink" (Clarke and Hancock, 2012).

A high NBF (positive and/or negative) indicates that there are "circular" payments in the system which cannot be netted out at a bilateral level. These circular payments can be seen as the level of dependency of each other's liquidity. This is illustrated by the matrices A, B, and $\mathrm{C}$ of Figure 1. Each matrix shows the payment flows of participants 1, 2, and 3. In matrix A both the NMF and the NBF are zero. The NBF is zero as each participant pays each other participant the exact same amount as it receives from that participant. Matrix $\mathrm{B}$ has an NMF equal to zero but the NBF is not equal to zero. The $N B F_{p o s}$ and $N B F_{\text {neg }}$ for bank $B_{1}$ is 90. Matrix $C$ (and most realistic one) shows a situation in which both the NMF and the NBF are unequal to zero. The NMF for e.g. participant $C_{1}$ is $55(100+25-30-40=55)$ and the $N B F_{\text {pos }}$ and $N B F_{\text {neg }}$ of this participant is 70 (with respect to participant $C_{2}$ ) and 15 (with respect to participant $C_{3}$ ), respectively.

Whereas in normal circumstances all in-flows and out-flows are "balanced," or can at least be absorbed by the available liquidity of participants, this balance is lost in case of a participant's failure and external liquidity may be needed to get all payments settled. 
Figure 1. Schematic Example of Payment Flows in a Three-Participant System

$$
\begin{aligned}
& A=\begin{array}{c}
1 \\
2 \\
3
\end{array}\left[\begin{array}{ccc}
0 & 100 & 3 \\
100 & 0 & 50 \\
10 & 50 & 0
\end{array}\right] \\
& B=\begin{array}{l}
1 \\
3
\end{array}\left[\begin{array}{ccc}
0 & 100 & 10 \\
10 & 0 & 100 \\
100 & 10 & 0
\end{array}\right] \\
& C=\begin{array}{l}
1 \\
2 \\
3
\end{array}\left[\begin{array}{ccc}
0 & 100 & 25 \\
30 & 0 & 50 \\
40 & 90 & 0
\end{array}\right]
\end{aligned}
$$

\section{B. Systemic Impact}

To measure the level of systemic impact we look at the number of participants that are affected by the failing one, which is the degree of that participant in the system. We do this by measuring the undirected degree of the failing participant as defined by Dorogovtsev and Mendes (2003). In addition, we look at the out and in degree of the failing participant. In case the failing participant has a positive outflow (NBFpos) the out-degree is taken and when it is negative (NBFneg) the in-degree. In the study of graphs and networks, the degree of a node in a network is the number of connections it has to other nodes and as such is a measure for interconnectedness.

The degree is calculated for every participant for every day in three varieties:

- $\quad$ Out-Degree: number of connections for outgoing payments

- In-Degree: number of connections for incoming payments

- Total Degree: number of connections for both incoming and outgoing payments.

A high degree stands for many links between the failing participant and other participants in the network. Subsequently, the impact of a failure of a participant with a high degree has a higher impact on the system than the failure of a participant with a lower degree.

\section{Combined Liquidity Risk and Systemic Impact}

The aim of this paper is to measure the liquidity risk and systemic impact of a participant simultaneously to determine the criticality of the failing participant using one composite risk indicator. 
Combining degree and NBFs/NMF per participant per day provides insight into the criticality of the failing participant. If the failing participant has many links to other participants and if the NBFs/NMF are high, then the failing participant is more critical to the system then when the number of links is low and the NBFs/NMF are low. We deem both liquidity risk and systemic risk as equally important in our total risk indicator. ${ }^{4}$

The total risk is defined as:

$$
\text { Total risk }=\sqrt{\left((\text { liquidity risk })^{2}+(\text { systemic } \text { risk })^{2}\right)}
$$

Directly comparing values in euro (NMF or NBF) with the degree value is not very meaningful as they are different types of variables. To make them comparable we normalize the NMF, NBF, and degree values. We do this by setting the largest euro value and degree observed in the data in a given quarter and set those values to 1 (one). All other euro values and degrees are scaled against these largest observed values and fall in the range between 0 (zero) and 1 (one). For illustration purposes we take a data sample of three months. Values close to 1 indicate a relatively high liquidity risk or systemic impact.

Figure 2 illustrates how to use the total risk measure graphically. We plot the liquidity risk (NMF or NBF) on the $\mathrm{x}$-axis and the systemic risk on the y-axis. Drawing circles with the origin as the central point of these circles represents combinations of liquidity risk and systemic impact. The larger the radius of the circle the larger the total risk will be.

Figure 2. Schematic Illustration of Measuring Level of Criticality

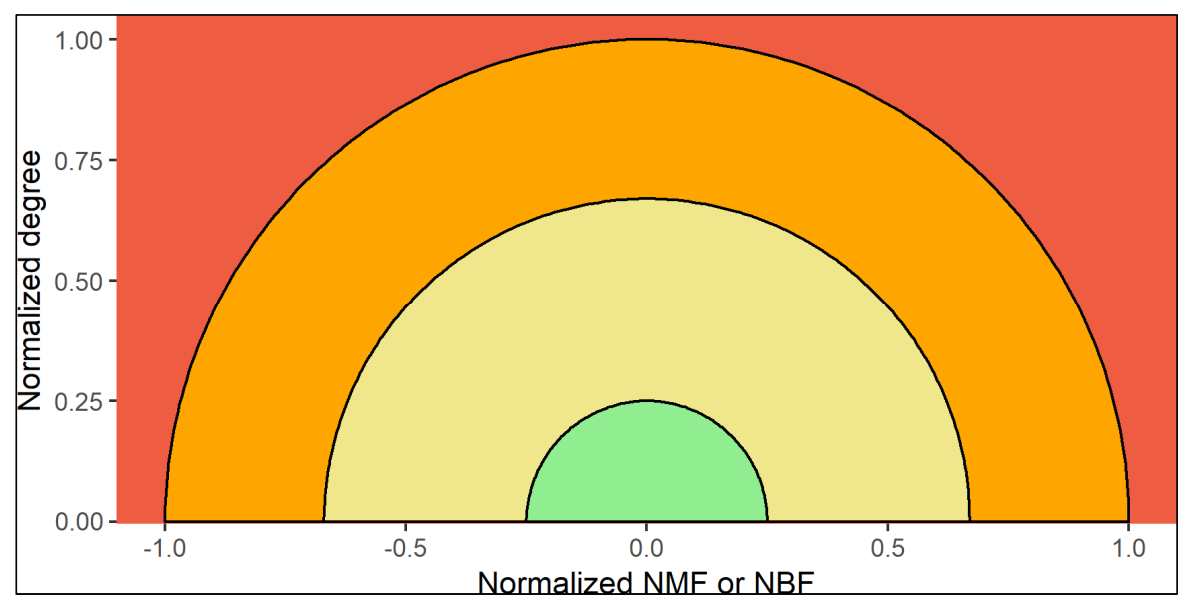

Source: Authors.

\footnotetext{
${ }^{4}$ It is possible to add different weights to the individual indicators if one indicator is deemed more important than the other.
} 
The figure contains three (semi) circles; one at one-third, one at two-third, and one at 1 . The colors go from green closest to the origin all the way to red outside the radius of 1 which stands for going from low risk to high risk, respectively. These radii can be set at any value for low, medium and high risk depending on the preferences of the expert in charge

In fact, the composite risk indicator can be seen as combining two typical indicators for systemic importance of an entity in one. Typical indicators to determine a financial institution's systemic importance comprise of its size, interconnectedness, cross-border activity, substitutability, and complexity (BCBS, 2013). The failure of a large, interconnected financial institution servicing multiple countries is more likely to negatively impact the system than the failure of a small institution that is only connected to a few counterparts in its national market. The systemic impact of an institution's failure is further negatively related to its degree of substitutability.

The composite risk indicator combines the NBFs/ NMF, which can be seen as an indicator for "size," with the degree which reflects "interconnectedness," which are often considered the most relevant indicators. In the context of the TARGET2 payment system, size would translate to the liquidity (in value of transactions) processed by participants, whereas interconnectedness would translate to the number counterparts. The indicator cross-border activity is difficult to translate to the TARGET2 environment since TARGET2 concerns a closed loop system for euro payments, without indication of cross-border activity. Also, substitutability is difficult to translate, however, it could be argued that FMIs are typically more difficult to substitute than banks, given their central role in markets.

\section{APPLICATION OF COMPOSITE RISK INDICATOR To TARGET2}

The composite risk indicator, as outlined in section III, is applied to the TARGET2 payment system to determine which TARGET2 participants are critical and what the potential impact is of their failure. First, the impact of the failure of a commercial bank is investigated, followed by an analysis of the impact of a failing FMI.

\section{A. Interbank: NMF/NBF Degree}

Figure 3a depicts the normalized degree against the NMF of three bank groups (light blue, green and red) for all 2017-2018 business days. Each dot reflects a position of a group on a specific business day.

The plot also shows three half circles with radius $1 / 3,2 / 3$ and 1 and the center at the origin, reflecting zero, low, medium, and high-risk levels of the indicator. If an observation lies outside the circle with radius 1 it is considered an outlier or potentially a high-risk situation, which according to the approach would cause the largest liquidity and systemic impact to the whole system. The light blue banks, near the horizontal axis in the graph show overall a low level of criticality since both their liquidity risk and systemic impact are low. These banks are not heavily connected and do not have a strong positive or negative liquidity position. The 
red group reflects banks which have a high degree, meaning they are very connected, and a large variation in liquidity positions. This group shows relatively large positive NMFs on certain days and on many days mid to high negative NMF values. On a regular basis these banks are highly critical to the system as a whole.

Figure 3. Composite Risk Indicator for Banks (2017-2018).

(a) Indicator using the NMF. For each business day and bank group there is one dot, reflecting the net multilateral flow in the period from 2017 to 2018.

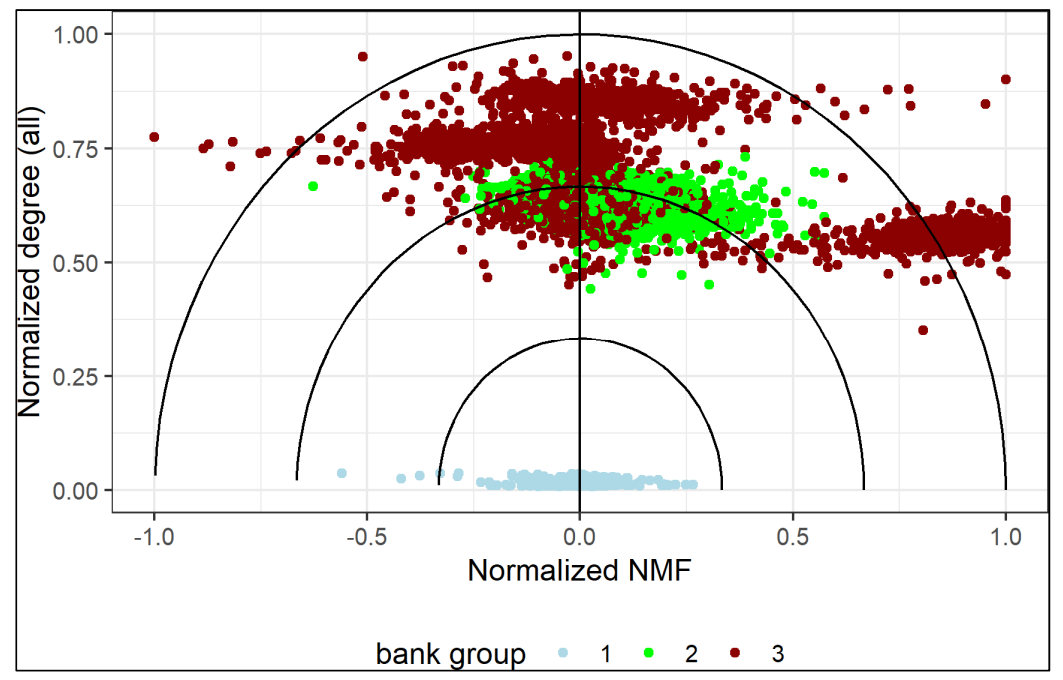

(b) Indicator using the NBF. For each business and bank group there are two dots, reflecting the positive and negative net bilateral flow in the period from 2017 to 2018 .

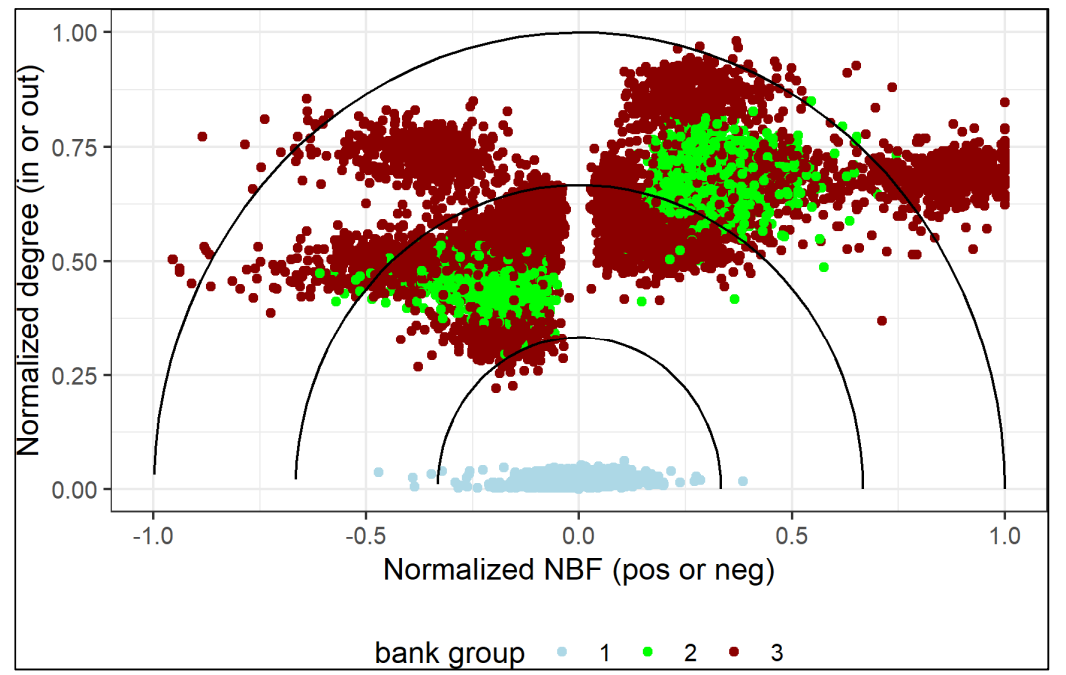

Note: The three different colors refer to the three different defined bank groups.

However, on many days their liquidity risk is relatively low (close to zero), which is the result of regular economic behavior of their clients (see e.g., Heijmans and Heuver, 2014). 
This means that the incoming and outgoing payments for this bank group fluctuate over the course of a month. As banks have to fulfil reserve maintenance requirements, they are required to maintain a certain positive balance on their account during the reserve maintenance period, see also Arciero, Heijmans, Heuver, Massarenti, Picillo, and Vacirca (2016). This group of banks may reflect banks with a high number of active retail clients initiating many low and high value payments. The green group reflects positions of banks in between the light blue and red banks with a higher connectivity to the system, but only slightly higher values of liquidity risk (NMF).

Figure $3 \mathrm{~b}$ shows the composite indicator similar to Figure $3 \mathrm{a}$ but then for the normalized degree and the NBFs. The red and green bank groups show no dots at the vertical axis, which means that they have a positive outflow with a part of the market and a positive inflow with the rest of the market. If banks in one of these groups default at least some of their counterparts will face a liquidity shortage, since they do not receive anticipated payments.

Each red dot outside the outer circle with a positive NMF and NBF indicates that there are substantial liquidity risks in case the entities representing this dot fail to send payments on that day. An entity's failure will impact multiple counterparts and the size of the multilateral and bilateral payment obligations is substantial. The dots outside the circle with a negative NMF and NBF reflect the risk that, in case the entities behind these dots fail to pay, payments may be trapped within their accounts as they may continue receiving payments but fail to forward these payments to their obligors. If an operational disruption results in a participant being unable to send payment instructions to the RTGS system for settlement, liquidity accumulates in that participant's account, the "liquidity sink." Such a disruption in liquidity recycling can prevent other participants from settling their payments.

Another conclusion from Figure 3 is that the number of dots reflecting a positive NMF and $\mathrm{NBF}$ is larger than the number of dots reflecting a negative NMF/NBF. This means that more participants potentially face a liquidity shortage than a liquidity sink. The light blue group is quite balanced with counterparts of these banks facing the same chance of being confronted with a liquidity shortage and a liquidity sink. The systemic impact of these events for the light blue group is, however, low.

Figure 4a focuses on a subset of data in Figure 3 by taking only data from the fourth quarter of 2018. This allows for analyzing a sample of the results in a shorter timeframe and comparing one period to another. The graph also distinguishes between the three different months of that quarter in order to compare one month to another. Comparing Figure 4a with Figure 3a shows that results are largely similar. A noticeable difference, however, is the absence of the tuft of red dots in Figure 4a, which is visible in Figure 3 outside the radius with a medium degree and a positive NMF. These differences indicate that banks' behavior is not necessarily constant over time. Such a temporary appurtenance may indicate a change in the network, which results in larger liquidity risk and/or systemic impact of such a participant failing. Figure $4 \mathrm{~b}$ shows the normalized degree against the positive and negative NBF. 
The outliers in Figure 4 reflect both positive and negative NMF and NBF values. The difference between the NMF and NBF is the impact of a failure towards the whole system versus individual counterparts (as a total). The majority of the outliers occurred in December. This may be due to the end of year cleaning up of the balance sheet, which is typically associated with higher activity in the payment system, see e.g. Heijmans, Heuver, and Walraven (2010).

Figure 4. Composite Risk Indicator for Banks (2018:Q4)

(a) Indicator using the NMF. For each business day and bank group in each month of the last quarter of 2018 there is one dot, reflecting the net multilateral flow.

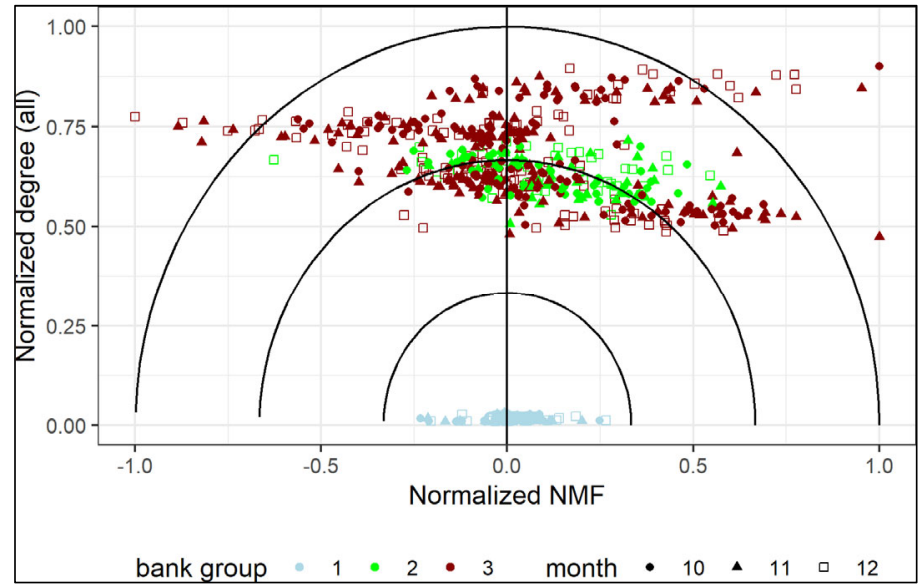

(b) Indicator using the NBF. For each business day and bank group in each month of the last quarter of 2018 there are two dots, reflecting the positive and negative net bilateral flow.

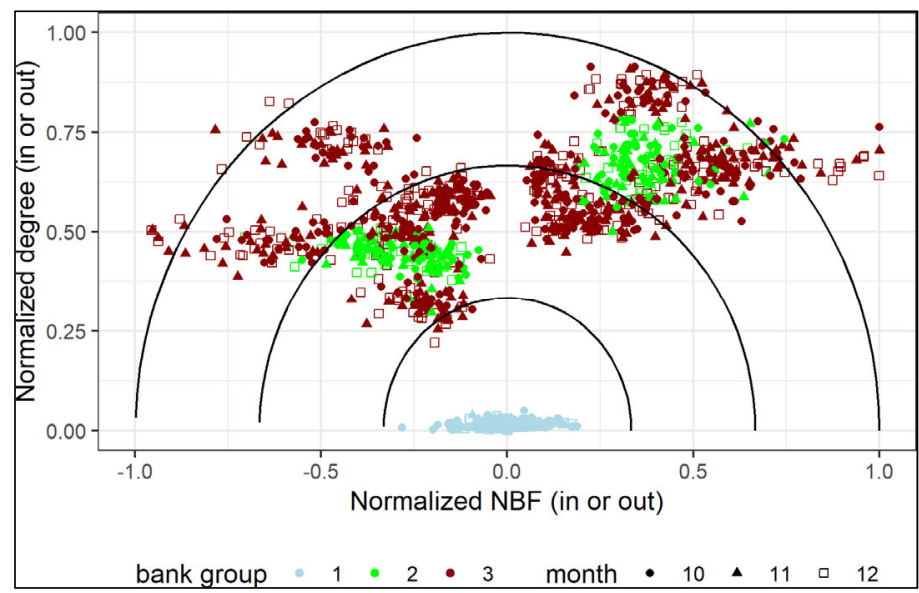

Note: The three different colors refer to the three different defined bank groups.

\section{B. FMIs: NMF/NBF Degree}

Figures 5 and 6 present observations for FMIs only for the same period without adjustments for the netting factor of ACHs, CCPs and other payment systems. Figure 6 adjusts the findings for the netting factor (Table 2). Instead of multiplying the euro values by this factor, 
we could also have changed the normalization to the new largest values, which would lead to values between zero and one. The previous graphs presented in this section, would lie much closer to the $y$-axis as a result. The principle of our method would, however, remain exactly the same.

The normalization of both the NMF/NBF and the degree is done with the same levels as for the banks, which allows for comparing the impact of banks to FMIs in TARGET2. Each dot represents the position of an individual FMI on a specific day. The graphs differentiate between ACHs, CCPs, CSDs and other payment systems. Similar as for banks, the dots beyond the circle with radius 1 would cause the largest liquidity and/or system impact to the system and to individual counterparts.

A first observation from Figure 5 is that results are different for different types of FMIs. Whereas CSDs vary widely in their degree, ACHs, CCPs and other FMIs typically have relatively low degrees (under the 0.33 -radius), indicating that the number of CSD participants can vary up to a high number, whereas the number of participants of ACHs, CCPs, and other FMIs is typically more contained. For example, participation in CCPs in typically concentrated in the largest banks due to the relatively high access criteria of CCPs. The sizes of the NMF and NBF are very low for CCPs, reflecting relatively small size payment instructions. An explanation for the relatively low degree of ACHs is that they are often active in one or a few countries, which results in a relatively small degree.

Figure 5. Composite Risk Indicator for FMIs (2018)

(a) Indicator using the NMF. For each business day and FMI there is one dot, reflecting the net multilateral flow in 2018.

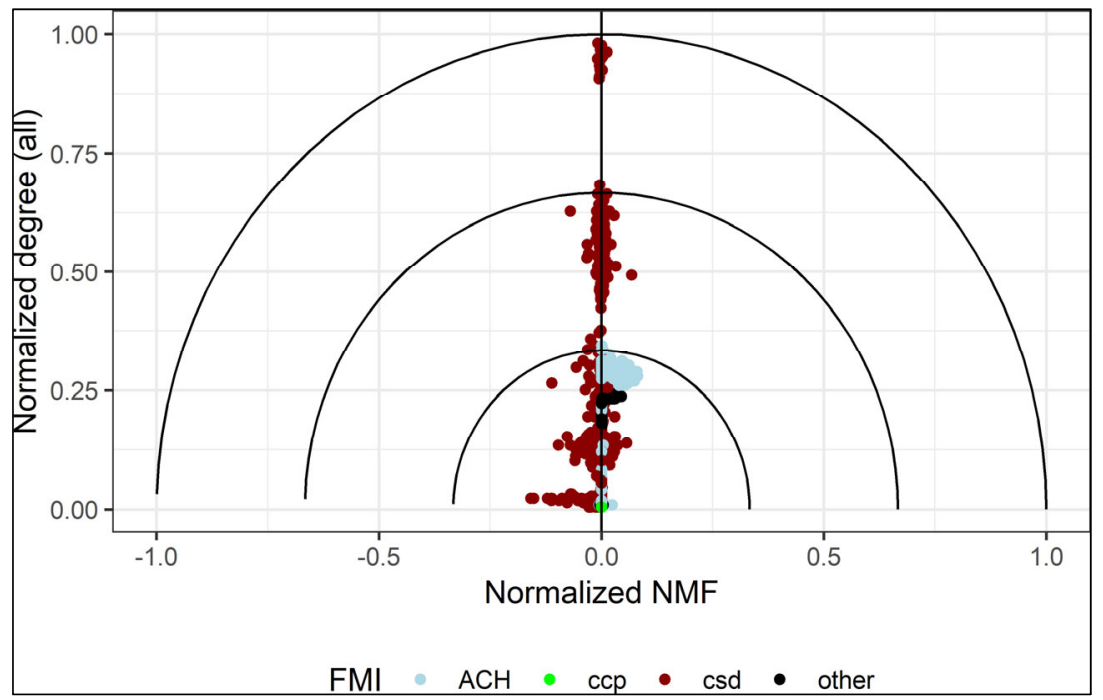


(b) Indicator using the NBF. For each business and FMI there are two dots, reflecting the positive and negative net bilateral flow in 2018 .

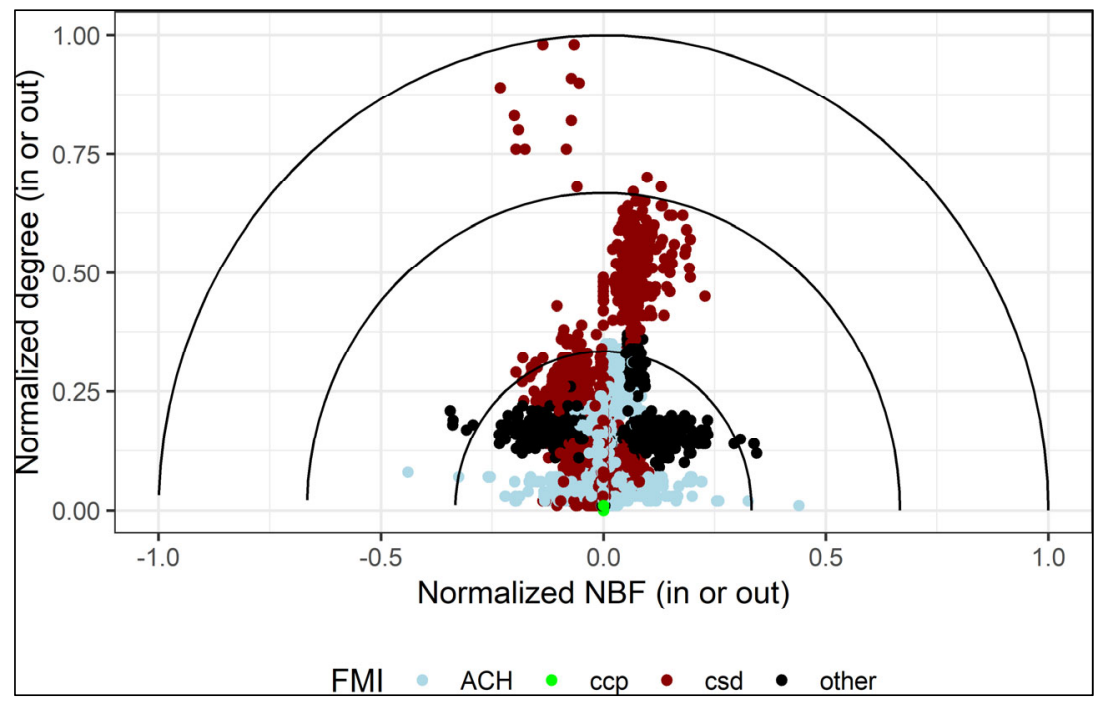

Note: FMls normalized against size of banks in Figure 3.

Each FMI type has a different color.

A second observation is that the NMF and NBF of FMIs are (much) lower than for banks. This can be explained by their specific role in the payments network, which includes netting services, for example in the case of ACHs handling retail payments from credit transfers, direct debits and card payments, and CCPs clearing securities and derivatives transactions. Their central role also requires a relatively lower level of liquidity balances in the payment system.

Third, the results for the NMF are clearly showing lower liquidity risks than for the NBF. This indicates that FMI participants individually may have high exposures to the FMI but that the FMI is a system in itself, often with a close to zero sum net result for the payment system. This means that the impact of a failing participant of, for example, a CCP can have a large impact on the overall position of that CCP as it will create unbalanced books at the CCP.

Fourth, Figure 5 shows that ACHs are usually paid in by fewer (large) participants then the number of participants they pay out to. This can be seen by the Figure $5 \mathrm{~b}$ which shows values for the normalized degree for which are substantially higher when the NBF is positive instead of negative. 
Figure 6. Composite Risk Indicator for FMls (2018:Q4)

(a) Indicator using the NMF. For each business day and FMI in each month of the last quarter of 2018 there is one dot, reflecting the net multilateral flow.

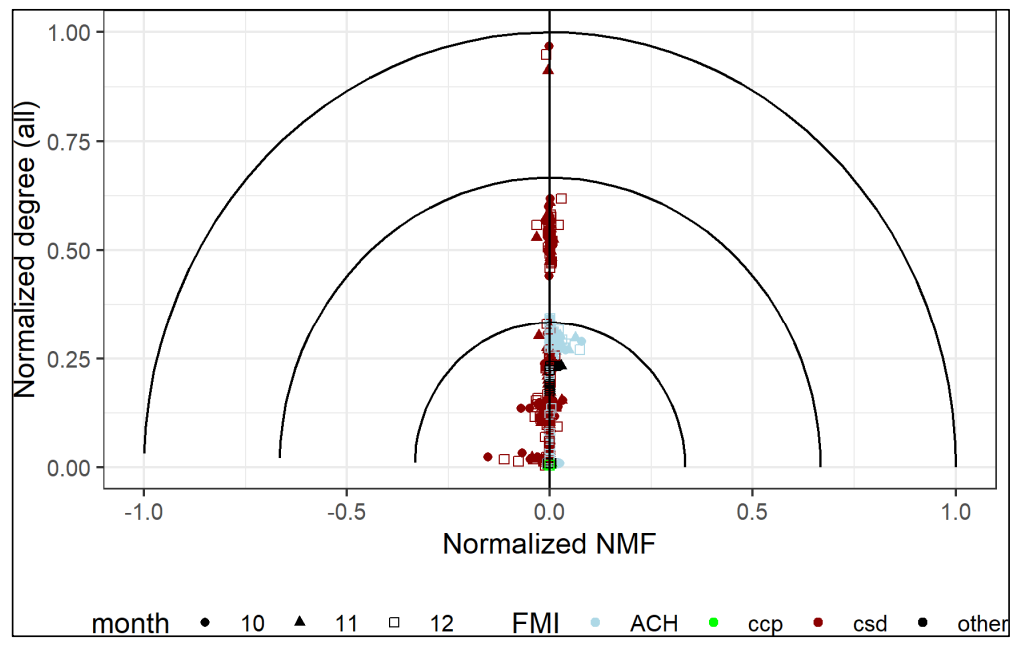

(b) Indicator using the NBF. For each business day and FMI in each month of the last quarter of 2018 there are two dots, reflecting the positive and negative net bilateral flow.

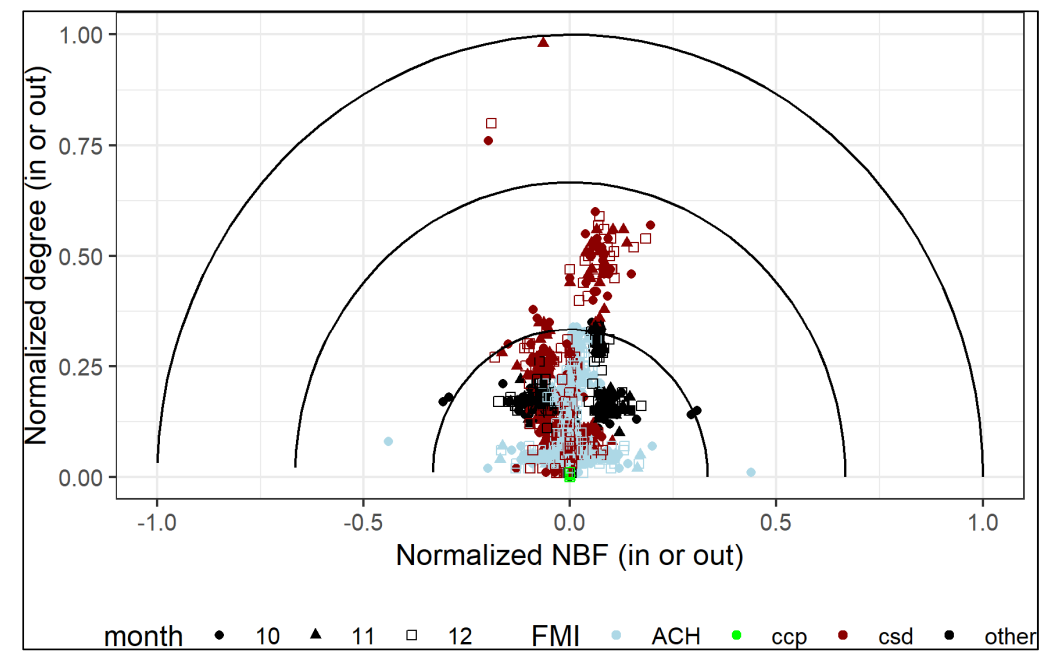

Note: FMls normalized against size of banks in Figure 3.

Another observation is that there do not seem to be large deviations between months.

Figure 6 illustrates that the business of an FMI is more stable than that of a bank, in terms of flows observed in TARGET2. This can be explained by the same factors as mentioned earlier. The netting factor balances out the largest cash movements, whereas the relatively low account balances of FMIs in TARGET2 are quite constant over time.

To compare the systemic risks of FMIs with banks the payment flows of FMIs need to be corrected for their netting ratio where relevant. If netting ratios are not considered, the observations misrepresent the FMIs' importance from a financial stability perspective. The 
multilateral netting applied by these FMIs results in less and smaller settlement instructions. However, in case one of these FMIs fails on its payment obligations the amount at risk can be much greater than the net amounts due. The NMF and NBFs are therefore corrected for their netting factor, using the factors of Table 2, with results presented in Figure 7. The "ellipses" are the circles that represent different levels of risk. They look like ellipses due to the different scale on the horizontal and vertical axes.

Furthermore, Figure 7 shows many outliers for the NMF for ACHs with many observations beyond the 1-radius. This seems to be the result of noise in the data with some outgoing transactions incorrectly being considered as part of the ACHs' core payments business. This data exaggerates the systemic importance of ACHs once multiplied by a factor 50 .

The most critical FMIs in TARGET2 in Q4 2018 have been the ACHs and "other FMIs" such as the wholesale payment systems CLS and EURO1. The high positive NMF and NBF reflect the substantial payment flows represented by these FMIs in TARGET2 and their critical importance for the liquidity of the system as individual participants. The bottom graph of Figure 7 shows very large values for the NBFpos and NBFneg for this group, indicating that the participants who pay in to, for example, CLS or EURO1 are different than the ones who get paid by these FMIs. Similarly, data for the ACHs also show large values of the positive and negative NBFs, however, not as extreme as for the large value payment systems CLS and EURO1.

CCPs and CSDs are less critical for the payment system. Although CCPs and CSDs are critical for financial stability this is not directly related to their role in the payment system. First, the size of payment instructions following securities transactions is relatively low given that securities markets are relatively small compared to the size of payment instructions in the wholesale and retail payment systems. Second, whereas for securities markets payments typically reflect the full-face value of the transactions, for derivatives markets payments typically only reflect margin calls, which are only a small percentage of the size of the exposure of the derivatives positions that are centrally cleared. Finally, the number of participants of CCPs is relatively low due to the concentration of investors and brokers in large banks that act as clearing member, given the strict capital, operational and other requirements to become a $\mathrm{CCP}$ participant. 
Figure 7. Composite Risk indicator for FMls, Adjusted for Netting Factor (2018:Q4)

(a) Indicator using the NMF.

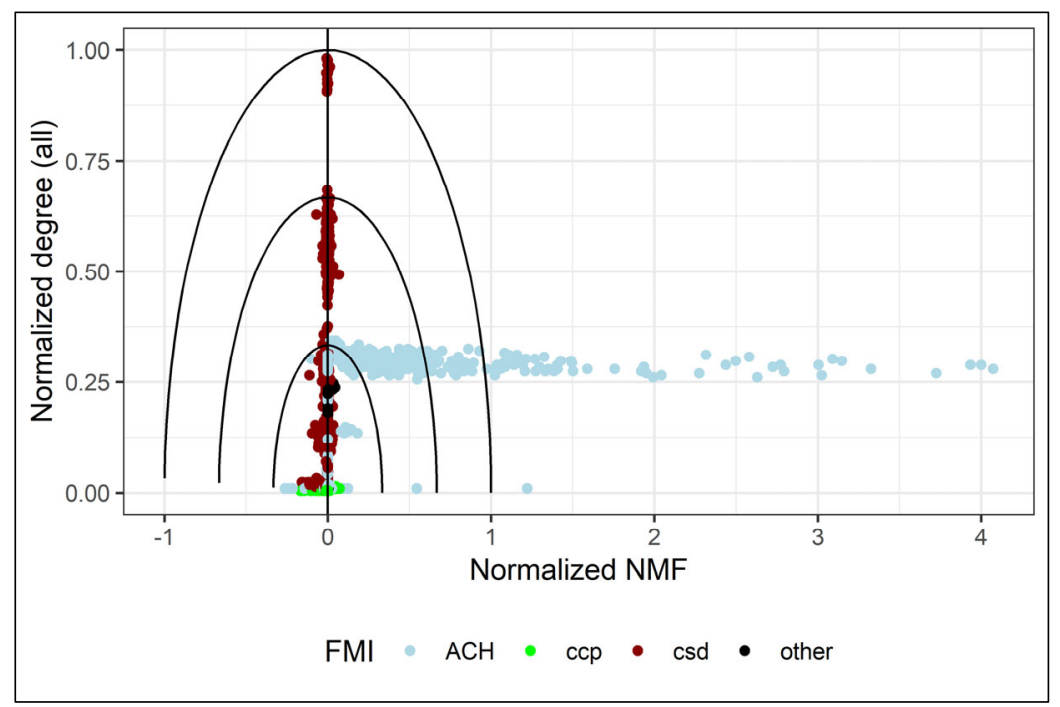

(b) Indicator using the NBF.

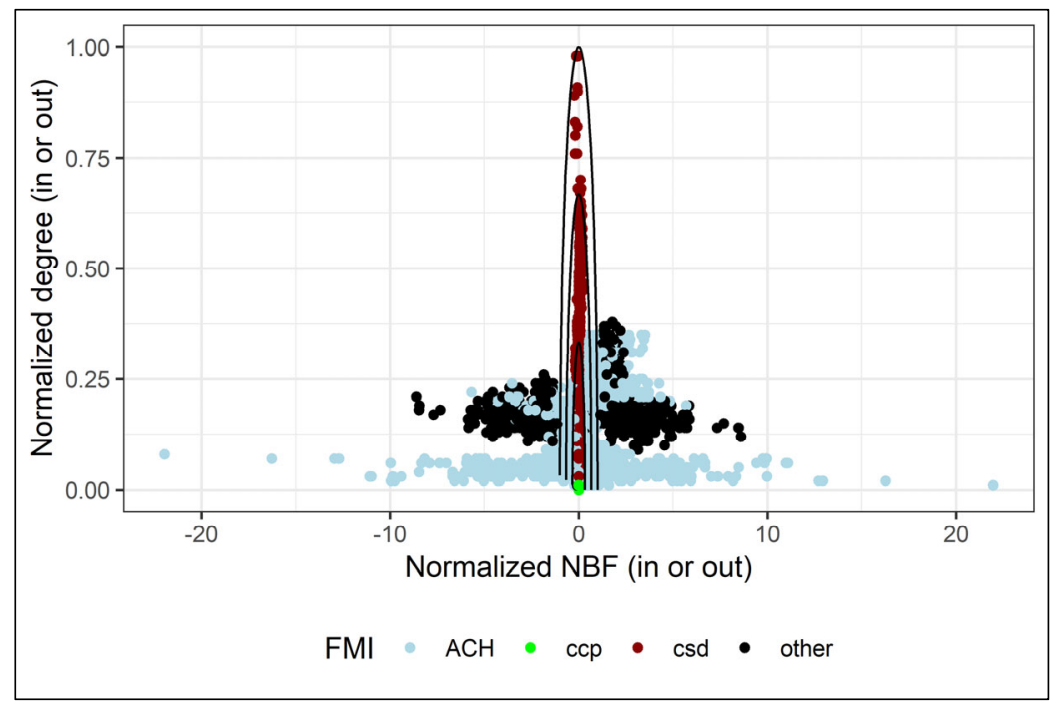

Note: FMls normalized against size of banks in Figure 3.

Two interesting conclusions can be drawn by comparing the criticality of banks versus FMIs (by comparing Figures 4 and 7). First, ACHs, and "other FMIs" are more critical than banks. This is a conclusion that was to be expected given the centralized position of FMIs and the concentration of payments within FMIs by nature. Second, FMIs' criticality seems not to be due to the degree, i.e., the number of counterparts, but clearly due to the size of the payments flows. Contrary, banks that are of critical importance are typically so because of their degree, indicating their central role in payments, for example, in case of correspondent banks. To 
what extent TARGET2 participants represent a broader set of economic actors that are clients of banks is difficult to extract from the available data.

\section{Policy Implications}

The findings illustrate that the composite risk indicator can be used for policy development by central banks (as operator and overseer of payment systems) and for general financial stability analysis. We identify at least four areas in which the composite risk indicator can be used.

First, the composite risk indicator is well designed to identify critical participants in a payment system. This supports the payment system operator in obtaining an integrated and comprehensive view of risks that the system bears from and poses to participants, including other FMIs, as required by PFMI Principle 3. Identification of critical participants allows the payment system operator to take measures to protect itself against operational and financial risks, for example, through monitoring of these participants and information sharing arrangements with relevant bank and FMI supervisors.

With regard to operational risks, PFMI Principle 17 suggests that "in some cases, an FMI may want to identify critical participants based on the consideration of transaction volumes and values, services provided to the FMI and other interdependent systems, and, more generally, the potential impact on other participants and the system as a whole in the event of a significant operational problem." Once identified these critical participants may need to meet some of the same operational risk-management requirements as the payment system itself, such as business continuity management, sufficient operational capacity, incident management, and physical and information security.

With regard to financial risks, identification of critical participants provides information about potential credit risks in case the payment system operator provides participants with intraday credit. Although exposures are covered by collateral, the value of collateral posted may fall below the amount of credit extended. Based on results about criticality, the payment system operator may consider whether specific precautionary measures for such participants should be introduced, so that their eventual default does not endanger the resilience of the infrastructure, for example, by defining limits on intraday credit extensions tailored to the criticality of the participant.

Second, understanding the risk profile of different types of FMIs may be used in discussions about central bank liquidity provision to non-bank financial institutions. While there is broad uniformity among central banks in granting banks access to an intraday and overnight liquidity facility in the RTGS system, access policies towards FMIs are more heterogeneous. Some countries allow FMIs that have an account in the RTGS system to access intraday and/or overnight liquidity (CPSS, 2003), while others explicitly do not. A common objective for central banks is to mitigate high concentrations of credit, liquidity and operational risk by providing a safe liquid settlement asset and a high degree of assurance of service continuity 
(CPSS, 2003). Also, moral hazard is relevant, where holders of settlement accounts may be misperceived to be within the safety net and hence likely to be eligible for liquidity assistance. Central banks may develop a policy framework which is based on an evaluation of benefits and risks that access to intraday and overnight liquidity brings. Such an evaluation can take into account the impact of access on monetary policy implementation, financial stability, market efficiency and neutrality, and costs for the central bank.

The composite risk indicator may be used as input to a central banks' cost-benefit analysis in determining whether it wants to open up its liquidity facility to a specific (type of) FMI and what type of liquidity is appropriate. The indicator allows to understand the risk that the FMI may pose as a participant to the payment system and what the potential liquidity risks may be for the system.

Third, crisis management arrangements will benefit from an enhanced understanding of the criticality of different payment system participants. This may inform scenarios that are used during business continuity drills, and general business continuity planning. Critical participants can also be invited to participate in business continuity exercises and general default management drills to help understand the complexity of decision making involving the different entities. Findings from the composite risk indicator may also feed in resolution planning of these banks for resolution authorities to tailor the potential use of resolution tools and strategies in such a way that they recognize the risks that a discontinuation of activities poses to other participants in the payment system.

Finally, financial stability experts and/or the central bank oversight function for payment systems can use the data for systemwide analysis of vulnerabilities. Oversight of payment, clearing and settlement systems is a central bank function whereby the objectives of safety and efficiency are promoted by monitoring existing and planned FMIs, assessing them against these objectives and, where necessary, inducing change (CPSS, 2005). The definition covers not only the assessment of particular systems against any oversight standards but also the broader activity of understanding the payment and settlement arrangements as a whole in an economy. This is important because of the links between FMIs (created by, for example, overlapping participation or by the use of one system to settle positions in another) and between FMIs and other financial institutions and markets. As such, the oversight objectives of a central bank are applied to the collective set of FMIs as well as individual FMIs. The broader understanding is also relevant for central bank's monetary and financial stability functions.

\section{Conclusions}

The composite risk indicator developed in this paper combines data on liquidity risk and systemic impact through interconnections among participants in order to determine the criticality of individual participants. This indicator is an informative and relatively easy data driven measure for determining the criticality of banks and settling FMIs in a payment 
system. Critical participants are those participants whose default could cause a significant problem for other participants of a market infrastructure. The indicator is a tool that can be used by central banks in function, notably payment system operations, payment system oversight, and general financial stability analysis. The overall objective is to increase understanding of links, vulnerabilities and contagion risks, and for strengthening the payment system operations.

Besides, knowing which participants represent the highest liquidity risk and/or systemic impact, as measured by our indicator, gives regulators an a-priori indication of the potential impact on the system as a whole. Detecting a very critical participant, whether it is a bank or FMI, may result in different interventions or procedures to prevent a failing participant from causing large damage to other participants and the broader financial system.

Finally, this paper is a new addition to the literature on network analysis for FMIs. Its added value relates to the use of payment transaction data, contrary to exposure data for interbank contagion models, to map interconnectedness and liquidity risks in payment systems. Furthermore, it allows for a comparison between the systemic importance of banks and FMIs, as well as among different types of FMIs, with cross-sectional takeaways that enhance the general understanding of interconnections in a payment system. 


\section{REFERENCES}

Arciero, L., R. Heijmans, R. Heuver, M. Massarenti, C. Picillo, and F. Vacirca (2016). How to Measure the Unsecured Money Market? The Eurosystem's Implementation and Validation using TARGET2 Data. International Journal of Central Banking March, 247280.

Arjani, N. and R. Heijmans (2020). Detecting operational outages from lvts transaction data. Payments Canada Discussion Paper, February.

Arjani, N., F. Li, and L. Sabetti (2020). Monitoring intraday liquidity risk in a real time gross settlement system. Payments Canada Discussion Paper, forthcoming.

Baek, S., K. Soramäki, and J. Yoon (2014). Network indicators for monitoring intraday liquidity in BoK-wire+. Journal of Financial Market Infrastructures 2(3), 37-66.

Bank of England, B. (2015). Independent review of RTGS outage on 20 October 2014: Bank of England's response.

Bardoscia, M., G. Bianconi, and G. Ferrara (2018). Multiplex network analysis of the UK OTC derivatives market. Bank of England Working Paper 726.

Berndsen, R. and R. Heijmans (2020). Risk indicators for financial market infrastructures: From high frequency transaction data to a traffic light signal. Journal of Risk 2(3), 39-64.

Bouveret, A. (2018). Cyber risk for the financial sector: A framework for quantitative assessment. IMF Working Paper.

CFTC (2019). CCP supervisory stress tests: Reverse stress test and liquidation stress test. CFTC Staff Report April.

Clarke, A. and J. Hancock (2012). Payment system design and participant operational disruptions.

Reserve Bank of Australia, Research Discussion Paper 2012-05.

CPSS (2003). The Role of Central Bank Money in Payment Systems. Bank for International Settlements.

CPSS (2005). Central bank oversight of payment and settlement systems. Bank for International Settlements.

CPSS-IOSCO (2012). Principles for Financial Market Infrastructures. Bank for International Settlements and International Organization of Securities Commissions.

Dorogovtsev, S. and J. Mendes (2003). Evolution of Networks. Oxford: Oxford University 
Press.

ECB (2019). Annual report 2018.

ESMA (2018). Eu-wide CCP stress test 2017. ESMA Report ESMA70-151-1154.

FSB (2017). Analysis of central clearing interdependencies. With BCBS, CPMI and IOSCO.

Glowka, M., J. Paulick, and I. Schultze (2018). The absence of evidence and the evidence of absence: an algorithmic approach for identifying operational outages in target2. Journal of Financial Market Infrastructures 6(2/3), 63-91.

Heijmans, R. and R. Heuver (2014). Is this bank ill? The diagnosis of doctor TARGET2. Journal of Financial Market Infrastructures 2(3), 3-36.

Heijmans, R., R. Heuver, I. Lelyveld, and C. Levallois (2016). Dynamic visualization of large financial networks. Journal of Network Theory in Finance 2(2), 1-23.

Heijmans, R., R. Heuver, and D. Walraven (2010). Monitoring the unsecured interbank money market using target 2 data. De Nederlandsche Bank Working Paper 276.

Heijmans, R. and C. Zhou (2019). Outlier detection in target2 risk indicators. DNB Working Paper (624).

IMF (2018), Jamaica Financial Sector Stability Assessment, IMF Country Report No. $18 / 347$.

Klee, E. (2010). Operational outages and aggregate uncertainty in the federal funds market. Journal of Banking and Finance 34(10), 2386-2402.

León, C., R. Berndsen, and L. Renneboog (2014). Financial stability and interacting networks of financial institutions and market infrastructures. Borradores de Economia 848 .

León, C. and J. Pérez (2014). Assessing financial market infrastructures'systemic importance with authority and hub centrality. Journal of Financial Market Infrastructures.

Li, F. and H. Pérez-Saiz (2018). Measuring systemic risk across financial market infrastructures. Journal of Financial Stability 34, 1-11.

Pröpper, M., I. van Lelyveld, and R. Heijmans (2013). Network Dynamics of TOP Payments. Journal of Financial Market Infrastructures 1(3), 3-29.

Rosati, S. and S. Secola (2005). Explaining Cross-border Large-value Payment Flows - 
Evidence from TARGET and Euro 1 Data. ECB Working Paper Series 443.

Soramäki, K., W. Beyeler, M. Bech, and R. Glass (2007). New Approaches for Payment System Simulation Research. In H. Leinonen (Ed.), Simulation studies of liquidity needs, risks and efficiency in payment networks., Proceedings from the Bank of Finland Payment and Settlement System Seminars 2005, pp. 15-40. Soramäki, K. and S. Cook (2013).

Sinkrank: An algorithm for identifying systemically important banks in payment systems. Economics: The Open-Access, Open-Assessment E-Journal 28(7).

Squartini, T., I. van Lelyveld, and D. Garlaschelli (2013). Early-warning signals of topological collapse in interbank networks. Scientific Reports 3(3357), 1-9.

Wendt, F. (2015). Central counterparties: Addressing their too important to fail nature. Journal of Financial Market Infrastructures 4(1), 59-84. 